\title{
Three-Dimensional Observations on Intermediate Filaments of the Squamous Epithelium of the Uterine Cervix
}

\author{
Naohiro Oikawa, Toshiniko Toki, Toru Tase, Yuichi \\ WADA and AkIRA YaJima \\ Department of Obstetrics and Gynecology, Tohoku \\ University School of Medicine, Sendai 980
}

\begin{abstract}
Oikawa, N., Toki, T., Tase, T., Wada, Y. and YaJima, A. ThreeDimensional Observations on Intermediate Filaments of the Squamous Epithelium of the Uterine Cervix. Tohoku J. exp. Med., 1985, $147(2), 169-176 —$ The following conclusions have been drawn from electron-microscopic threedimentional observations on the intermediate filaments (IFs) of the squamous epithelium from the uterine cervix. (1) IFs form a three-dimensional reticular network and wrap around the intracellular periphery of cells extending from the basal to the superficial layers. (2) In basal and parabasal cells, the IFs are distributed in a pattern radiating from the perinuclear location toward the cellular periphery. (3) The use of PEG-embedding method after detergent-extraction with Triton X-100 and saponin is suitable for the three-dimensional observations on IFs of stratified squamous epithelium from the uterine cervix.__ intermediate filaments; sguamous epithelium; uterine cervix; immersion extraction; stereo electron microscopy
\end{abstract}

In stratified squamous epithelium, keratin is a major differentiation product and can be observed as a filament of approximately $10 \mathrm{~nm}$ diameter [the so-called intermediate filament (IF)] (Steinert and Idler 1975; Sun and Green 1978). Through conventional electron microscopic procedures, IFs can be observed in cytoplasm, however, it is still difficult to understand how IFs are distributed three-dimentionally.

In the present paper, we report our electron microscopic three-dimensional observation on IFs of the squamous epithelium from the uterine cervix, using polyethylene glycol (PEG) (Wolosewick 1980) after detergent-extraction of cytoplasmic soluble proteins.

\section{Materials and Methods}

Tissue preparation and embedding in $P E G$

Materials were tissues obtained after hysterectomy for benign diseases such as myoma

Received February 13, 1985 ; accepted for publication July 24, 1985. 
uteri. The squamous epithelial portion of the uterine cervix was removed immediatelly following hysterectomy and carefully cut into $1-2 \mathrm{~mm}^{3}$ blocks in PHEM buffer $(60 \mathrm{mM}$ PIPES at $\mathrm{pH}$ 6.9, $25 \mathrm{mM}$ HEPES, $10 \mathrm{mM}$ EGTA, $2 \mathrm{mM} \mathrm{MgCl}_{2}$ ) (Schliwa and van Blerkom 1981). In order to wash out cytoplasmic proteins, the blocks were treated with detergent solutions $\left(0.3 \%\right.$ Triton $\mathrm{X}-100,0.05 \%$ saponin, PHEM buffer) at $37^{\circ} \mathrm{C}$. The saponin was added simultaneously to the Triton to remove the granular material on the surface of the IFs (Hirokawa 1982). The extraction was allowed to proceed for 5-6 hr, after which the blocks were washed with PHEM buffer. The detergent-extracted blocks were then fixed with $2 \%$ glutaraldehyde in PHEM buffer for $60 \mathrm{~min}$ at room temperature. The blocks were washed three times with $0.2 \mathrm{M}$ phosphate buffer $\mathrm{pH} 6.9$ ( $5 \mathrm{~min}$ each wash). The blocks were postfixed with $0.4 \% \mathrm{OsO}_{4}$ in phosphate buffer $0.1 \mathrm{M}$ for $40 \mathrm{~min}$ at $4{ }^{\circ} \mathrm{C}$ and subsequently washed in distilled water.

The blocks were dehydrated through a series of increasing ethanol concentrations ending with three changes of $100 \%$ ethanol for 20 min each, and subsequently incubated in a series of $50 \%$ PEG (MW=6,000, Sigma Chemical Co.) in 100\% ethanol (vol/vol), $75 \%$ $\mathrm{PEG}$ and $100 \%$ molten PEG at $60^{\circ} \mathrm{C}$, each for $4 \mathrm{hr}$ (Wolosewick 1980). They were transferred to gelatin capsules filled with fresh $100 \%$ molten PEG and cooled at room temperature.

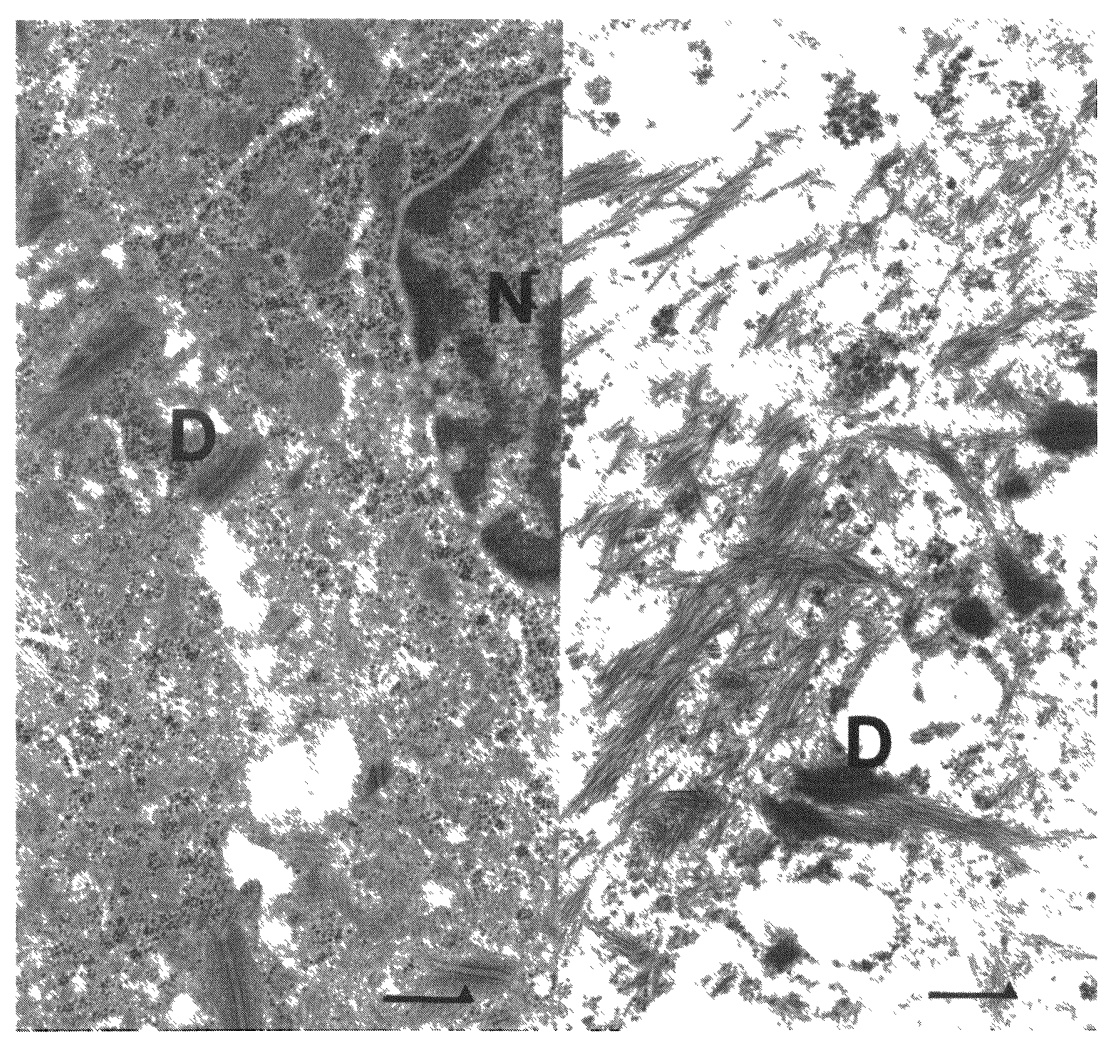

Fig. 1. Electron micrographs of parabasal cells of the statıfied squamous epithelıum from a uterine cervix. Epoxy-embedded section. Left: Non-treated control. Right: Treated with Triton X-100 and saponin. D, desmosome; $\mathrm{N}$, nucleus Original magnification $\times 12,000 . \quad B a r=0.36 \mu \mathrm{m}$. 


\section{Sectioning and removal of $P E G$}

The PEG-embedded blocks were cut using dry glass knives at about 500 to $700 \mathrm{~nm}$ thickness on MT-5000 ultramicrotome (DuPont Instruments-Sorvall, Newtown, Ct, USA). Then the sections were transferred from the knife to a petri dish filled with distilled water, and mounted onto Formvar-coated, carbon-stabilized copper grids that had been treated with poly-L-lysine $(0.1 \%$ in distilled water, $\mathrm{MW}=15,000$, Sigma Chemical Co.) (Mazia et al. 1975). The grids were transferred to another fresh distilled water, then dehydrated through an ethanol series and dried through the $\mathrm{CO}_{2}$ critical point (Ishii et al. 1984). Sections were examined in Hitachi $\mathrm{H}-600$ electron microscope at $100 \mathrm{kV}$.

\section{Epon-Araldite embedding}

The blocks were extracted, fixed, and dehydrated as described above, then infiltrated with the resin through a graded series of propylene oxide and epoxy mixture. The blocks were placed in embedding molds containing fresh Epon-Araldite and allowed polymerize in an oven at $60^{\circ} \mathrm{C}$ for 2 days. Thin sections (silver gold interference color) were cut on MT-5000 ultramicrotome using diamond knives. Sections were stained in lead citrate, uranyl acetate and again in lead citrate (Hamilton et al. 1967) and examined in Hitachi $\mathrm{H}-600$ electron microscope at $75 \mathrm{kV}$.

For the purpose of comparison, non-extracted blocks were fixed with $2 \%$ glutaraldehyde in $0.1 \mathrm{M}$ phosphate buffer $\mathrm{pH} 7.2$ for $2 \mathrm{hr}$ and postfixed with $1 \% \mathrm{OsO}_{4}$ in phosphate buffer $0.1 \mathrm{M}$ for $1 \mathrm{hr}$. Then they were embedded in Epon-Araldite and examined by conventional electron microscopic procedures.

\section{RESUlts}

\section{Electron microscopy of epoxy-embedded sections}

By detergent-extraction with $0.3 \%$ Triton $\mathrm{X}-100$ and $0.05 \%$ saponin, most of cell organelles were washed out, whereas filaments approximately $10 \mathrm{~nm}$ in thickness were visualized throughout the cytoplasm. On the left of Fig. 1 is shown a section which had been fixated immediately and from which intracellular soluble protein was not revomed. On the right is shown an ultrathin section in which the soluble protein had been removed. Both are parabasal cells. The filaments are mainly distributed in the periphery of the cytoplasm - mostly running in parallel with the cell membrane and a portion running toward desmosomes. Microtubules and microfilaments are not observed.

\section{Electron microscopy of PEG-embedded sections}

Fig. 2 shows a pair of stereo electron micrographs of the parabasal cells after detergent-extraction. IFs can be seen forming reticular networks and wrapping around the intracellular periphery.

It is also seen that some of the IFs are oriented toward the desmosomes, and the desmosomes are also seen to be connected by arching IFs to one another. Moreover, intermediate filaments are also seen to irradiate from a perinuclear location.

Fig. 3 is a high magnification view of a portion of parabasal cell. The individual fibers can be discerned, each of which is about $10 \mathrm{~nm}$ in diameter. 


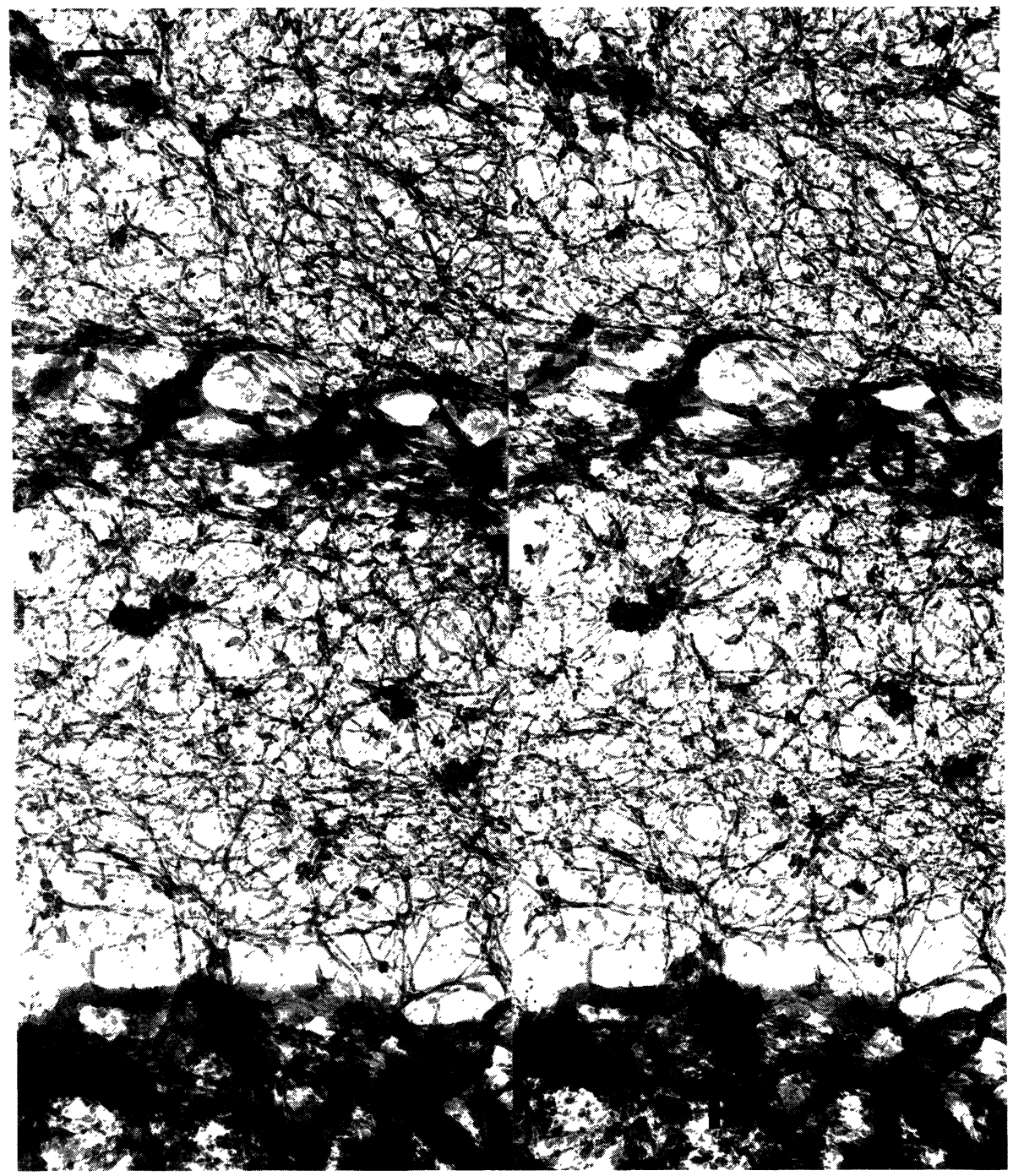

Fig. 2. Stereopair electron micrographs of parabasal cells treated with Triton $\mathrm{X}-100$ and saponin. PEG-embedded section. IFs form reticular networks and wrap around the cell periphery. Desmosomes are connected by arching IFs to one another. Moreover, IFs irradiate from a perinuclear location to the periphery. D, desmosome, $\mathrm{N}$, nucleus. Original magnification $\times 15,000$. $\mathrm{Bar}=0.27 \mu \mathrm{m} . \quad \pm 10^{\circ}$ tilt.

Larger filaments of $20 \mathrm{~nm}$ maximal diameter can also be seen.

The stereo electron micrographs in Fig. 4 afford a three-dimensional view of an intermediate layer cell. It is apparent that the IFs are distributed in a three-dimensional network similar to that described above. 


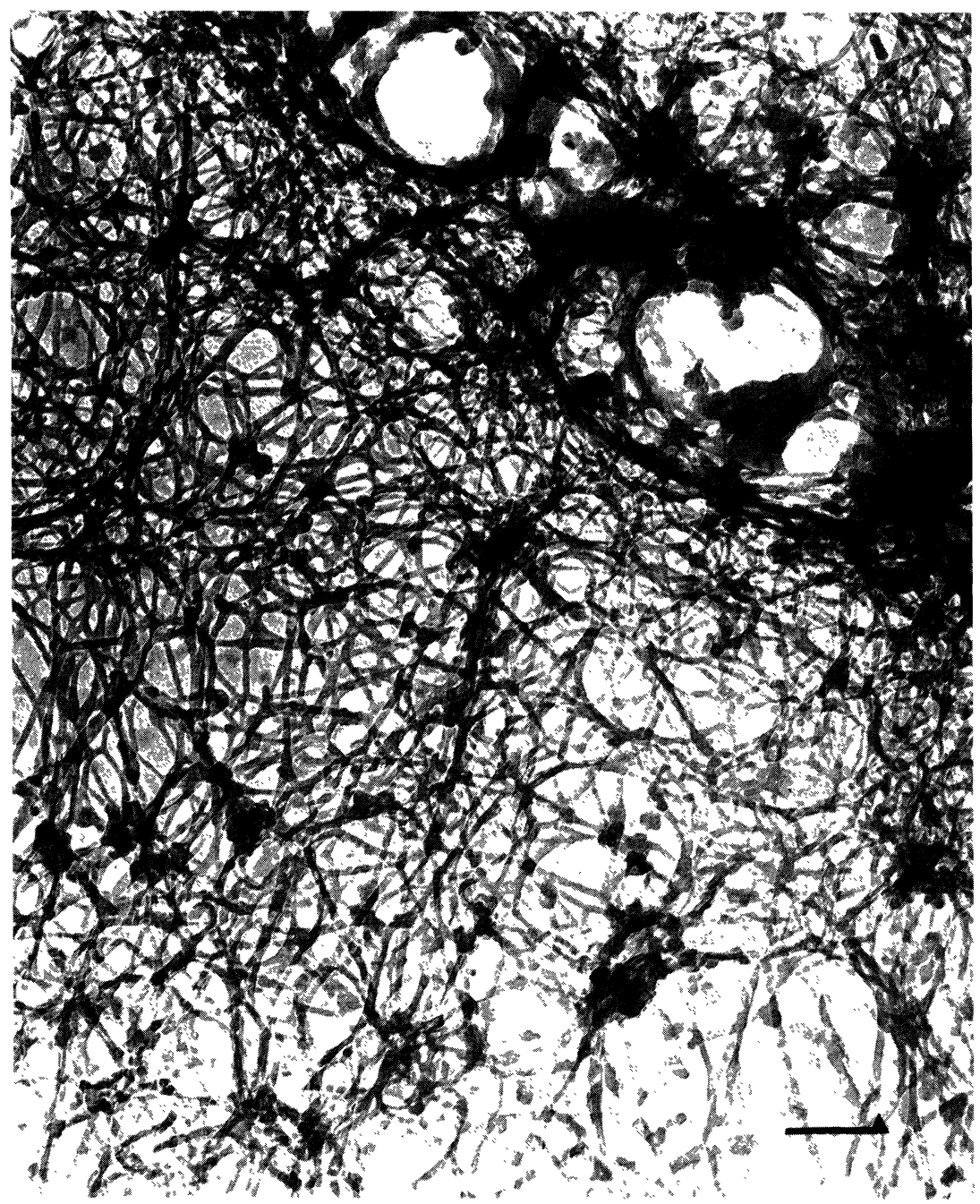

Fig. 3. High magnification micrographs of parabasal cells treated with Triton X-100 and saponin. PEG-embedded section. The individual fibers can be discerned, each of which is about $10 \mathrm{~nm}$ in diameter. Larger filaments of 20 $\mathrm{nm}$ maximal diameter can also be seen. D, desmosome. Original magnification $\times 30,000$. $\mathrm{Bar}=0.18 \mu \mathrm{m}$.

\section{Discussion}

Conventional thin section is essentially a two-dimentional slice of threedimensional objects whose actual morphology can only be reconstructed with difficulty. Transmission electron microscopic (TEM) images formed from these thin sections are suitable for visualizing many biological structures but are inappropriate for examining three-dimensional networks of filamentous structures such as those constituting the cytoskeletal framework. 


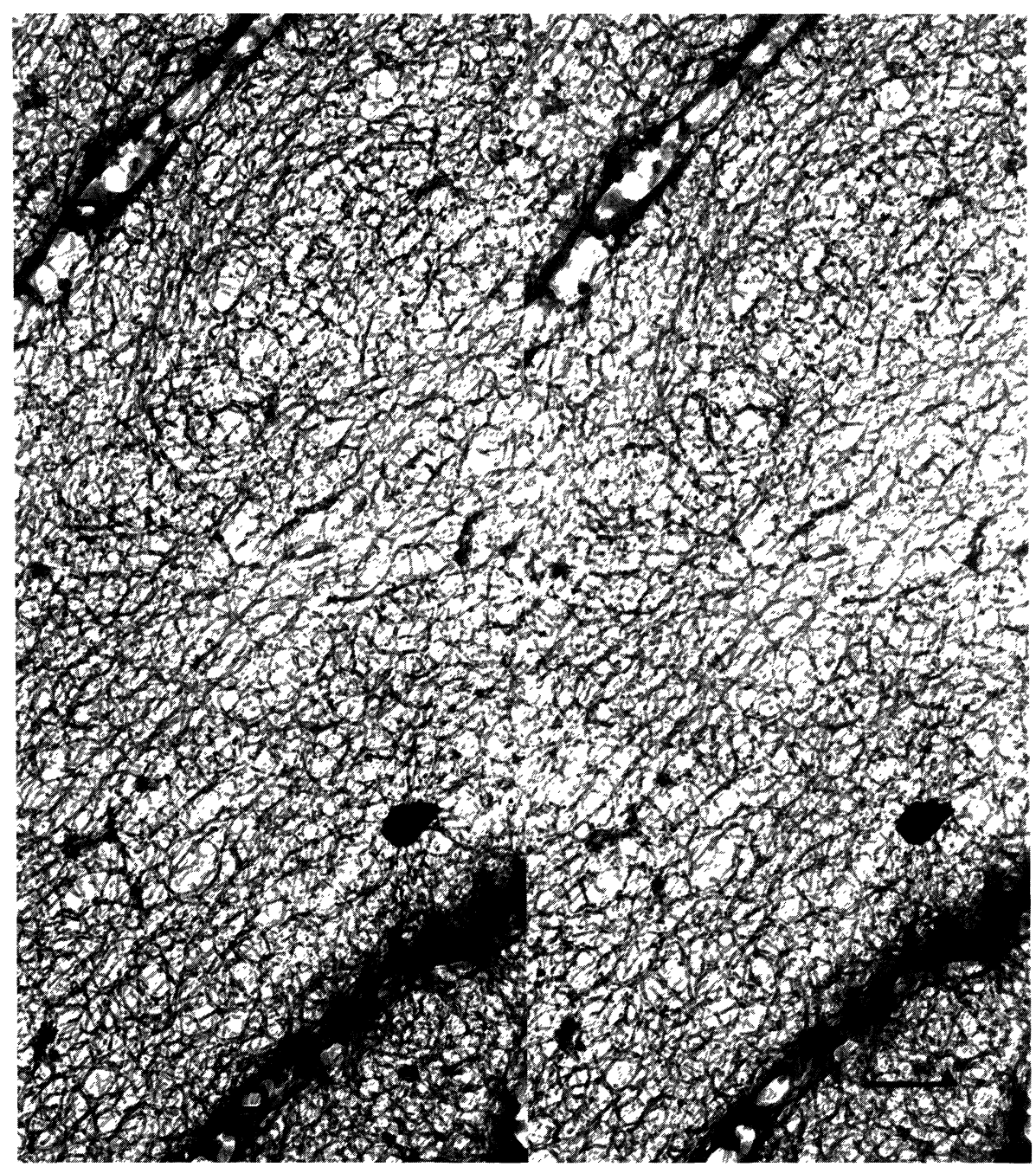

Fig. 4. Stereopair electron micrographs of intermediate cells treated with Triton X-100 and saponin. PEG-embedded section. IFs are distributed in a threedimentional network similar to parabasal cells. D, desmosome. Original magnification $\times 15,000 . \quad \mathrm{Bar}=0.36 \mu \mathrm{m} . \quad \pm 10^{\circ}$ tilt.

The selective extraction of soluble proteins prior to fixation and the use of unembedded whole mounts provide a three-dimensional observation of cytoskeletal framework in culture cells (Buckley and Porter 1975; Wolosewick and Porter 1976). Wolosewick (1980) reported the use of PEG as an embedding medium for obtaining embedding-free sections of in situ tissues for ultrastructual studies. He presented an image of cell ultrastructure unobscured by electronscattering resins, similar to the image of unembedded, whole mount cultured cells observed by TEM. We attempted to three-dimensionally visualize the cytos- 
keleton of stratified squamous epithelium from the human uterine cervix by PEG-embedding method after detergent-extraction.

The immersion extraction with Triton X-100 and saponin enhances the visualization of the cytoskeletal elements. The intercellular junctions appear to be sufficiently maintained and the distribution of cytoskeletal frameworks is also well-established. From the electron microscopic observations of epoxy-embedded sections, the filaments resistant to the extraction with Triton X-100 and saponin are thought to represent IFs. Microtubules and microfilaments are mostly washed out and scarcely observed. The extraction method we used here seems to be suitable for visualizing IFs of stratified squamous epithelium but inappropriate for examining microtubules and microfilaments.

The observations on PEG-embedded sections show the individual coursing of the IFs. They were found to have diameters in agreement with those reported in previous studies, although some of the filaments observed by us had maximal diameters of approximately $20 \mathrm{~nm}$. Such filaments are thought to be bundles of several IFs and to demonstrate the limitations of the PEG-embedding technique.

IFs are observed to form reticular networks and wrap around the intracellular periphery. Moreover, a part of IFs are also seen to irradiate from a perinuclear location and extend to the periphery of the cell. These findings shown here are very similar to those of cultured cell shown by Jones et al. (1982). With regard to the functions of IFs, these findings suggest that IFs are intimately involved in maintaining epithelial cell shape, nuclear centering, and cell-to-cell contact throughout the entire tissue (Jones et al. 1982).

\section{References}

1) Buckley, I.K. \& Porter, K.R. (1975) Electron microscopy of critical point dried cultured cells. J. Microsc., 104, 107-120.

2) Hamilton, R.L., Regen, D.M., Gray, M.E. \& LeQuire, V.S. (1967) Lipid transport in liver. I. Electron microscopic identification of very low density lipoproteins in perfused rat liver. Lab. Invest., 16, 305-319.

3) Hirokawa, N. (1982) Cross-linker system between neurofilaments, microtubules, and membranous organelles in frog axons revealed by the quick-freeze, deep-etching method. J. Cell Biol., 94, 129-142.

4) Ishii, M., Suzuki, H., Ohta, S., Otsuki, M. \& Goto, Y. (1984) Morphologic study of cytoskeletal system of mouse hepatocytes using polyethylene glycol-embedding method. Tohoku J. exp. Med., 142, 299-311.

5) Jones, J.C.R., Goldman, A.E., Steinert, P.M., Yuspa, S.H. \& Goldman, R.D. (1982) Dynamic aspects of the supramolecular organization of intermediate networks in cultured epidermal cells. Cell Motility, 2, 197-213.

6) Mazia, D., Schatten, G. \& Sale, W. (1975) Adhesion of cells to surfaces coated with polylysine. J. Cell Biol., 66, 198-200.

7) Schliwa, M. \& van Blerkom, J. (1981) Structural interaction of cytoskeletal components. J. Cell Biol., 90, 222-235.

8) Steinert, P.M. \& Idler, W.W. (1975) The polypeptide composition bovine epidermal $\alpha$-keratin. Biochem. J., 151, 603-614.

9) Sun, T.-T. \& Green, H. (1978) Keratin filaments of cultured human epidermal cells. 
J. biol. Chem., 253, 2053-2060.

10) Wolosewick, J.J. (1980) The application of polyethylene glycol (PEG) to electron microscopy. J. Cell Biol., 86, 675-681.

11) Wolosewick, J.J. \& Porter, K.R. (1976) Stereo high voltage electron microscopy of whole cells of the human diploid cell line WI-38. Amer. J. Anat., 147, 303-324. 